\title{
La potestad expropiatoria del Estado en el derecho español y colombiano ${ }^{1}$
}

\section{The expropriatory power of the State in Spanish and Colombian law}

\author{
DOI: http://dx.doi.org/10.17981/juridcuc.14.1.2018.5
}

Artículo de investigación. Fecha de recepción: 28/11/2017 Fecha de aceptación: 21/06/2018

\author{
Jimmy Antony Pérez Solano \\ Universidad del Norte (Colombia) \\ pjimmy@uninorte.edu.co
}

Para citar este artículo:

Pérez, J. (2018). La potestad expropiatoria del Estado en el derecho español y colombiano. JURÍDICAS CUC, vol. 14, no. 1, pp. 105-118. DOI: http://dx.doi.org/10.17981/juridcuc.14.1.2018.5

\section{Resumen}

La potestad expropiatoria de los Estados está determinada por el concepto que se tenga de la función social de la propiedad. En ese cometido, es clave tener presente que la potestad expropiatoria cuenta con un fundamento normativo constitucional y legal, donde el concepto que se tenga de la propiedad, en la medida en que esta "tenga" o "sea" una función social, determina los lineamientos bajo los cuales se ejerce la potestad expropiatoria. Lo anterior implica hacer una lectura de la propiedad privada a la luz de los Estados Sociales de Derecho español y colombiano en un ejercicio de derecho comparado que tiene como finalidad revisar de manera detallada el fundamento de la potestad expropiatoria para, así, lograr establecer semejanzas y diferencias que permitan establecer el alcance de la expropiación en los respectivos ordenamientos jurídicos.

Palabras claves: propiedad, función social, derecho fundamental, expropiación, potestad expropiatoria, acciones legales

\begin{abstract}
The States' power to expropriate is determined by how its property's social function is understood. In doing so, it is essential to consider that the expropriation authority has a legal and constitutional policy rationale in which the concept given to the property -insofar this "is" or "has" a social purpose-, determines the guidelines under which the power of expropriation is applied. The foregoing implies a reading of the private property in the light of the Spaniard and Colombian Social States under the rule of law in a comparative law exercise that aims to review in detail the basis of the expropriatory power. This, in order to establish similarities and differences and allow to establish the scope of the expropriation in its respective legal orders.

Keywords: property, social function, fundamental right, expropriation, expropriation authority, legal action
\end{abstract}

\footnotetext{
${ }^{1}$ Este artículo es resultado de la investigación titulada: La función social de la propiedad y la potestad expropiatoria del Estado en el derecho español y colombiano, realizada por la especialización en derecho administrativo en la Universidad de Salamanca, España.

The author; licensee Universidad de la Costa - CUC. 


\section{INTRODUCCIÓN}

La potestad expropiatoria sobre el derecho de dominio sobre un bien recae y se desarrolla como interrupción o limitación en el disfrute de un bien en contra de quien se hace llamar su propietario o dueño y, por parte y a favor, de un Estado que así lo requiere. Esta afectación al derecho de propiedad o de dominio tiene un doble componente. De una parte, limita el uso y el goce de los bienes a quienes fueron inicialmente sus propietarios, $\mathrm{y}$, de otra parte, garantiza la disposición del bien para el uso y disfrute de la generalidad, al punto de llevar a que el derecho de propiedad pase a manos del Estado en el momento que así lo requiera para el logro de sus fines.

Hoy día sigue discutiéndose si la llamada función social de la propiedad privada, "tiene" o "es" una función social, de manera que uno u otro alcance determina la trascendencia de la potestad expropiatoria de cada Estado. Por ello, se utilizó como metodología el análisis comparado de los preceptos constitucionales de uno y otro país en torno al tema objeto de estudio, persiguiendo con ello desentrañar y concluir lo que se considera el fundamento de la potestad expropiatoria en el Derecho español y en el colombiano.

\section{La potestad expropiatoria del Estado en el Derecho español}

Previo a abordar lo concerniente a la potestad expropiatoria, conviene precisar que la misma está marcada por la función social que llegare a tener la propiedad. En el Derecho español, la propiedad tiene una función social, tal como puede extraerse de lo dispuesto en el artículo 33 Constitucional, y que en palabras de García expresa que "esta dirección doctrinal vendría a condensarse en la máxima siguiente: la propiedad tiene una función social, pero no es una función social" (García, 2007, p. 293), constituyendo un presupuesto conceptual y jurídico de la potestad expropiatoria. Los particulares tienen derechos de dominio, pero relativizados en función de los requerimientos del Estado, quien deberá siempre surtir los procedimientos admi- 
nistrativos o judiciales del caso para poder expropiar o limitar el derecho de dominio de los particulares en beneficio de un interés colectivo, procediendo, como es natural, al consecuencial pago de las indemnizaciones cuando a ello hubiere lugar (Pérez, 2016, p. 189).

Ahora bien, de acuerdo con lo expresado por el profesor Eduardo García de Enterría (2006):

La potestad expropiatoria es un poder abstracto y genérico, ordinariamente derivado de status legales y no originable por convenciones legales, cuyo efecto consiste en la modificación de las situaciones jurídicas existentes (potestades innovativas) o en el mantenimiento, realización o tutela de situaciones jurídicas preexistentes, sin modificarlas o innovarlas; no tiene una referencia específica a un objeto concreto, no supone, como el derecho subjetivo, especificidad de objeto dominado, sino que se extiende a un marco genérico de posibles objetos; no encuentra enfrente, decíamos, obligados singulares, prestaciones o actuaciones debidas, sino más bien $<<$ sujeciones $>>$, vinculación puramente pasiva de soportar la realización de sus efectos propios. (p. 52).

Esta comprensión de la potestad expropiatoria del profesor García de Enterría sigue siendo actual. Si se mira el contenido del artículo 33 de la Constitución española se puede encontrar, en primer término (33.1), que se reconoce el derecho a la propiedad privada y a la herencia, con lo que se le da contenido y fundamento al derecho de propiedad y una garantía al mismo. En segundo lugar (33.2), que hay una función social de la propiedad que estará delimitada por las leyes que se profieran con ese fin, de ahí lo originariamente derivado, tal como lo señalaba el profesor García de Enterría. En tercer lugar (33.3), se fijan parámetros objetivos para la privación de los derechos de propiedad de los particulares como es la utilidad pública o el interés social debidamente justificado, y con la correspondiente indemnización cuando afecta el núcleo esencial del derecho (Barcelona, 2013, p. 7).

No debe perderse de vista que la garantía patrimonial de que goza el particular está dada, de una parte, por una defensa $a$ 
priori del Estado del derecho de propiedad del particular, y, de otra parte, un respeto por los derechos del particular que deben ser cedidos para el beneficio de la comunidad por justificadas razones de utilidad pública o interés social. Todo lo anterior, poniendo de presente la eventual responsabilidad civil de la Administración en tanto que afecte el núcleo esencial del derecho de propiedad con la disposición que, a la postre, se dé con los bienes expropiados.

Nótese además que en la vigente Constitución española (1978), no se hace referencia explícita a la expropiación, pero el contenido de lo allí regulado así lo sugiere de manera inequívoca. En su lugar se refiere a la "privación del derecho". Es ahí donde cobra mayor importancia el papel del legislador al darle contenido concreto al precepto constitucional, tal como lo hizo con todas aquellas normas de rango legal y reglamentario que parecieran estar dispersas en el ordenamiento jurídico, en especial por el sistema autonómico, pero pese a ello se pueden señalar como principales las contenidas en el Código Civil (Real Decreto de 24 de julio de 1889); en la Ley 16 de expropiación forzosa (1954), conocida como "Ley de expropiación forzosa"; en el Decreto de 26 de abril de 1957, mediante el cual se aprueba el reglamento de la ley de expropiación forzosa. Así mismo, todas aquellas relativas a la expropiación, entre las cuales se puede mencionar el Decreto Legislativo 2/2008 del 20 de junio sobre expropiación en materia de urbanismo; ${ }^{2}$ la Ley $29 / 1994$ del 24 de noviembre, en materia de vivienda; la Ley 22/1998 del 28 de julio, en materia de obras públicas, transporte y comunicaciones; la Ley 22/1973 del 21 de julio, en materia de minas e hidrocarburos; el Real Decreto Legislativo 1/2000 del 20 de julio, en materia de aguas; la Ley 54/1997 del 27 de noviembre, en materia de industria; la Ley 16/1985 del 25 de junio, en materia de patrimonio histórico; el Real Decreto del 10 de marzo

\footnotetext{
${ }^{2}$ Este es un tema de gran impacto y relevancia actual en España y que sirve de lineamiento para contrastar con el Derecho colombiano. El asunto fue puntualmente expuesto por el profesor Dr. Juan Ramón Fernández Torres, dentro de los $37^{\circ}$ Cursos de Especialización en Derecho y con toda solvencia y profundidad en su libro Estudio integral de las expropiaciones Urbanisticas. Segunda Edición. Cizur Menor (Navarra): Thomson- Aranzadi, el cual fue insumo importante para delimitar el tema del presente trabajo.
} 
de 1881, en materia de defensa nacional (expropiación forzosa por necesidades militares del ramo de guerra en tiempos de paz); y la Ley 7/1985 del 2 de abril, reguladora de las bases del régimen local, entre otras.

No sobra advertir que muchas de estas normas son anteriores al precepto constitucional al cual están sujetas, y aun así han permanecido vigentes, con lo cual puede decirse que en ese sentido han sido pocas las inconstitucionalidades normativas sobrevinientes ${ }^{3}$ en lo que atañe a este derecho en concreto y que ha permitido una mayor armonización respecto del concepto y contenido del derecho de propiedad.

Sin embargo, siendo las anteriores el fundamento de la potestad expropiatoria del Estado español, no son pocas las críticas que se hacen al manejo que se le da al derecho de propiedad, en especial lo que concierne a las regulaciones autonómicas con relación a las expropiaciones urbanísticas, y, en cualquier caso, al tema del justiprecio que siempre está al orden del día, en tanto que, o no se reconoce un cuantum indemnizatorio ante ciertas limitaciones al derecho de propiedad, o se justiprecia con una disparidad entre lo que considera el expropiado y lo que se determina por parte del Estado en el caso en concreto, generando no pocas controversias entre los involucrados.

Precisamente, esa es una de las críticas iniciales que se le hizo a la Ley de expropiación forzosa (1954), dado que la potestad expropiatoria fue fundamentalmente construida por la ley en su sentido material y allí fue donde se dejó el tema del justiprecio sin unos claros parámetros que permitieran hacer justicia de forma objetiva.

En todo caso, "desde el punto de vista jurídico la potestad expropiatoria se justifica in concreto por la atribución de la ley, así como más en particular por el efecto operativo de las causae expropiandi que la ley tipifique" (García, 2006, p. 53). Y es aquí donde se debe distinguir que, una es la situación de hacer las declaratorias de utilidad pública o interés social del

\footnotetext{
${ }^{3}$ Por ejemplo, la derogatoria que se hizo del Fuero de los Españoles por la derogatoria primera de la constitución del 27 de diciembre de 1978 (Escuin, 2008).
} 
bien a expropiar en los términos del artículo 9 de la Ley de expropiación de 1954, y otra diferente, pero consecuente, es su procedimiento expropiatorio, legitimado por la constitución y la ley, provisto de un sistema garantista para el sujeto expropiado, al menos en teoría. Distorsión que, si se quiere, es corregible en la medida en que se logre un riguroso consenso al respecto.

\section{La potestad expropiatoria del Estado en el Derecho colombiano}

Por su parte, la propiedad en Colombia es una función social, y bajo ese entendido se erige como el principal presupuesto de la potestad expropiatoria. La propiedad es una función social en sí misma, distinto del Derecho español en el que la propiedad "tiene" una función social al punto de considerársele un derecho fundamental. En ese sentido, en Colombia, el Estado, a través de las acciones establecidas para su defensa, podrá ejercer la potestad expropiatoria respetando el marco jurídico dentro del cual se preserven los derechos fundamentales, de manera que por "ser" la propiedad privada una función social, el Estado permite el goce al particular del derecho de dominio, pudiéndolo retomar en cualquier momento (Pérez, 2016, p. 188).

La potestad expropiatoria en el Derecho colombiano emana directamente de la Constitución Política, que en su artículo 58 sienta las bases del derecho de propiedad, sus alcances, sus limitaciones y sus funciones sociales y ecológicas al servicio del bien común, así como las posibilidades de disposición de dicha propiedad para fines de utilidad pública e interés social.

Es así como la Constitución Política de Colombia (1991), en su artículo 58 dispone:

Artículo 58. Se garantizan la propiedad privada y los demás derechos adquiridos con arreglo a las leyes civiles, los cuales no pueden ser desconocidos ni vulnerados por leyes posteriores. Cuando de la aplicación de una ley expedida por motivos de utilidad pública o interés social, resultaren en conflicto los derechos de los particulares con la necesidad por ella reconocida, el interés privado deberá ceder al interés público o social. 
La propiedad es una función social que implica obligaciones. Como tal, le es inherente una función ecológica.

El Estado protegerá y promoverá las formas asociativas y solidarias de propiedad.

Por motivos de utilidad pública o de interés social definidos por el legislador, podrá haber expropiación mediante sentencia judicial e indemnización previa. Esta se fijará consultando los intereses de la comunidad y del afectado. En los casos que determine el legislador, dicha expropiación podrá adelantarse por vía administrativa, sujeta a posterior acción contenciosaadministrativa, incluso respecto del precio. [negrillas fuera de texto].

Teniendo en cuenta que la norma constitucional dejó en manos del legislador ${ }^{4}$ la determinación de los motivos de la utilidad pública, así como lo relacionado con los casos en que dicha expropiación se haga por vía administrativa, se expidió la Ley 388 (1997), modificatoria en su mayoría de la Ley 9 (1989), por la cual se dictan normas sobre planes de desarrollo municipal, compraventa y expropiación de bienes y se dictan otras disposiciones.

En ese sentido la Ley 388 (1997), en su artículo 59, estableció como entidades competentes para adquirir por motivos de utilidad pública o interés social, por enajenación voluntaria o decretar la expropiación de inmuebles, las siguientes: 1) la Nación, 2) las entidades territoriales, 3) las áreas metropolitanas y 4) las asociaciones de municipios. Así mismo, se dispuso que podrán hacerlo: 5) los establecimientos públicos,

\footnotetext{
${ }^{4}$ La Corte Constitucional, mediante Sentencia C-216 (1993), en ese sentido expresó: "La Constitución, cuando se refiere al legislador y no específicamente al Congreso, permite que los motivos de utilidad pública o de interés social sean definidos excepcionalmente por el Ejecutivo, investido, desde luego, de las precisas facultades extraordinarias contempladas en su artículo 150 , numeral $10^{\circ}$ (76, numeral 12, de la Carta Política anterior, a cuyo amparo se expidieron las normas atacadas), vale decir, en su calidad de legislador extraordinario. Se hace posible el excepcional procedimiento de la expropiación y se afecta mediante éste el derecho del propietario no para dar satisfacción a intereses privados, sino por razones que favorecen el beneficio colectivo, lo cual hace legítimo y constitucional que el propietario pierda su derecho para contribuir a los fines sociales siempre y cuando se cumpla en su integridad con los presupuestos y requisitos que la Carta exige. En las normas demandadas no se plasma una posibilidad de expropiación por interés distinto al público, ni se produce la situación descrita en la demanda, según la cual unos particulares expropiarían a otros." Cfr. Sentencia C-536/1997 de la Corte Constitucional.
} 
6) las empresas industriales y comerciales del Estado y 7) las sociedades de economía mixta asimiladas a las anteriores, de los órdenes nacional, departamental y municipal que estén expresamente facultadas por sus propios estatutos para desarrollar alguna o algunas de las actividades previstas en el artículo 58 de la Ley 388 (1997).

De conformidad con esta norma, los inmuebles se podrán adquirir para destinarlos a los siguientes fines (Ley 388, 1997):

(...)

a. Ejecución de proyectos de construcción de infraestructura social en los sectores de la salud, educación, recreación, centrales de abasto y seguridad ciudadana;

b. Desarrollo de proyectos de vivienda de interés social, incluyendo los de legalización de títulos en urbanizaciones de hecho o ilegales diferentes a las contempladas en el artículo 53 de la Ley 9 (1989), la rehabilitación de inquilinatos y la reubicación de asentamientos humanos ubicados en sectores de alto riesgo;

c. Ejecución de programas y proyectos de renovación urbana y provisión de espacios públicos urbanos;

d. Ejecución de proyectos de producción, ampliación, abastecimiento y distribución de servicios públicos domiciliarios;

e. Ejecución de programas y proyectos de infraestructura vial y de sistemas de transporte masivo;

f. Ejecución de proyectos de ornato, turismo y deportes;

g. Funcionamiento de las sedes administrativas de las entidades públicas, con excepción de las empresas industriales y comerciales del Estado y las de las sociedades de economía mixta, siempre y cuando su localización y la consideración de utilidad pública estén claramente determinados en los planes de ordenamiento o en los instrumentos que los desarrollen;

h. Preservación del patrimonio cultural y natural de interés nacional, regional local, incluidos el paisajístico, ambiental, histórico y arquitectónico; 
i. Constitución de zonas de reserva para la expansión futura de las ciudades;

j. Constitución de zonas de reserva para la protección del medio ambiente y los recursos hídricos;

k. Ejecución de proyectos de urbanización y de construcción prioritarios en los términos previstos en los planes de ordenamiento, de acuerdo con lo dispuesto en la presente Ley;

1. Ejecución de proyectos de urbanización, redesarrollo y renovación urbana a través de la modalidad de unidades de actuación, mediante los instrumentos de reajuste de tierras, integración inmobiliaria, cooperación o los demás sistemas previstos en esta Ley;

m. El traslado de poblaciones por riesgos físicos inminentes (art 58).

Como se ve, la potestad expropiatoria de origen constitucional y con pleno desarrollo legal es el marco jurídico dentro del cual tanto el juez (en instancia judicial), como el servidor público (en instancia administrativa), una vez se dan los presupuestos fácticos, proceden a declarar bienes como de utilidad pública o de interés social previo a decretar las expropiaciones, bien por la vía judicial o por la vía administrativa, según sea el caso, tal como dispone la Ley 388 (1997) en los artículos 58 a 62, referidos a la adquisición de inmuebles por enajenación voluntaria y expropiación judicial, y los artículos 63 a 72, referidos a la expropiación por vía administrativa. Se pone de presente que suelen presentarse igualmente las disparidades o, al menos, desencuentros entre lo que en un momento dado considera como justo precio por parte del propietario expropiado y lo que considera apropiado el Estado al momento de expropiar, máxime cuando los justiprecios de los bienes se realizan con parámetros claros y previamente establecidos en el ordenamiento jurídico y de manera (inicialmente) concertada, acudiendo a terceros imparciales que se encargan de cumplir ese cometido a favor de todos los involucrados. 
Convergencias y divergencias conceptuales en torno a la potestad expropiatoria en el Derecho español y colombiano

- En relación con las actuaciones administrativas en el procedimiento expropiatorio, se tiene que en el Derecho español hay una clara distinción entre el procedimiento administrativo y el debido proceso, entendiendo este último como propio de las actuaciones judiciales y no de las actuaciones de la Administración. En este sentido, difiere sensiblemente con el Derecho colombiano donde las actuaciones de los jueces y las autoridades administrativas están enmarcadas por la protección constitucional al debido proceso, de tal suerte que situaciones como ausencia de notificaciones o actuaciones fuera del plazo vician las legalidades del acto y del procedimiento mismo, mientras que en el Derecho español ello no tiene lugar. En este último caso, el interés jurídicamente tutelado es la eficacia de la administración pública, por lo tanto, salvo que se trate de un procedimiento administrativo sancionatorio, en el Derecho Administrativo español no hay lugar a alegar el debido proceso en estas actuaciones administrativas, simplemente habría una irregularidad no invalidante.

- Tratándose de la motivación de los actos administrativos mediante los cuales se ejerce la potestad expropiatoria, se tiene que, tanto en el Derecho español como en el colombiano, es aspecto común la garantía de la legalidad de la fundamentación y del derecho del que gozan los ciudadanos para que las decisiones de la Administración que estén encaminadas al ejercicio de la potestad expropiatoria estén debidamente motivadas, en especial cuando se trata de subordinar el derecho a la propiedad privada por motivos de utilidad pública o el interés general, en tanto que cuanto mayor es la discrecionalidad de las decisiones administrativas, mayores deben ser las motivaciones (Pérez, 2016, p. 188).

- Tanto para el Derecho español como para el Derecho colombiano, cobran especial relevancia las expropiaciones. Son asuntos siempre actuales y de relevancia atemporal por ser un derecho que siempre está en la base de todos los ordenamientos jurídicos en los distintos momentos históricos. 
Es por ello que el Derecho Administrativo moderno hay que interpretarlo y aplicarlo desde la óptica de los derechos fundamentales, haciendo prevalecer la juridicidad que involucra todo el ordenamiento jurídico (aún el supranacional) por encima de la simple legalidad como garantía de la tutela judicial efectiva de un derecho (propiedad) siempre controversial.

- Finalmente, se puede extraer de lo analizado que, tanto en el Derecho español como en el colombiano, la función social de la propiedad es un presupuesto conceptual y jurídico de la potestad expropiatoria, pero el contenido de esa función social es diferente en cada uno de estos países, lo que a la postre fija unos presupuestos dentro de los cuales se ejerce dicha potestad sin que ello desconozca o limite el ejercicio de la misma.

\section{Conclusiones}

La potestad expropiatoria o el derecho a despojar del derecho de dominio al particular que esté en poder de bienes que interesen al Estado con fines que beneficien a la colectividad cuenta con pleno respaldo constitucional y legal para afectar los intereses privados en beneficio de los intereses colectivos. El de la propiedad, es un derecho con carácter limitado, y ese límite lo va fijando el ejercicio de la potestad expropiatoria, al punto que si bien el Estado garantiza su adquisición, uso y disfrute por parte de los particulares, es éste mismo Estado quien lleva a que tales derechos de dominio pasen de las manos de aquellos a manos de éste en el momento que así se requiera para el logro de los fines estatales, por lo que se puede concluir que la función social de la propiedad es un presupuesto esencial de la potestad expropiatoria en ambos ordenamientos jurídicos, de manera que el concepto que se tenga de la función social de la propiedad determinará los límites bajo los cuales se ejercerá dicha potestad en cada Estado.

\section{REFERENCIAS}

Barcelona, J. (2013). Propiedad, privación de la propiedad y expropiación en el sistema del Convenio Europeo de Derechos Humanos. Madrid: Centro de Estudios Políticos y Constitucionales. 
República de Colombia. Congreso de la República. (11 de enero de 1989). Por la cual se dictan normas sobre planes de desarrollo municipal, compraventa y expropiación de bienes y se dictan otras disposiciones. [Ley 9]. Diario Oficial No. 38.650. Recuperado de http://www.alcaldiabogota.gov.co/sisjur/normas/ Norma1.jsp?i=1175

República de Colombia. Congreso de la República. (18 de julio de 1997). Por la cual se modifica la Ley 9 de 1989, y la Ley 2 de 1991 y se dictan otras disposiciones. [Ley 388]. Diario Oficial No. 43.091. Recuperado de http://www.alcaldiabogota.gov.co/ sisjur/normas/Norma1.jsp?i=339

República de Colombia. Corte Constitucional (Pleno). (9 de junio de 1993). Sentencia C-216/93. [M.P. José Gregorio Hernández Galindo]. Recuperado de http://www.corteconstitucional.gov. co/relatoria/1993/C-216-93.htm

República de Colombia. Corte Constitucional (Pleno). (23 de octubre de 1997). Sentencia C-536/97. [M.P. Antonio Barrera Carbonell]. Recuperado de http://www.corteconstitucional.gov.co/ relatoria/1997/C-536-97.htm

República de Colombia. Asamblea Nacional Constituyente. (1991). Constitución Política de Colombia. Gaceta Constitucional No. 116. Recuperada de http://www.senado.gov.co/images/stories/ Informacion_General/constitucion_politica.pdf

Escuin, V. (2008). Comentarios a la ley de expropiación forzosa. Tercera Edición. Cizur Menor (Navarra): Thomson - Civitas.

Reino de España. (18 de marzo de 1978). Constitución Española.

Recuperada de http://www.congreso.es/docu/constituciones/ 1978/1978_cd.pdf

Reino de España. Ministerio de Gracia y Justicia. (24 de julio de 1889). Por el que se publica el Código Civil. [Real Decreto]. Boletín Oficial del Estado núm. 206. Referencia: BOE-A-1889-4763. Recuperado de https://www.boe.es/buscar/pdf/1889/BOE-A1889-4763-consolidado.pdf

Reino de España. Jefatura del Estado. (16 de diciembre de 1954). Sobre expropiación forzosa. [Ley 16]. Boletín Oficial del Estado núm. 351. Referencia: BOE-A-1954-15431. Recuperado de https://www.boe.es/boe/dias/1954/12/17/pdfs/A08261-08278. pdf 
Reino de España. Ministerio de Justicia. (26 de abril de 1957). Por el que se aprueba el Reglamento de la Ley de Expropiación Forzosa. [Decreto]. Boletín Oficial del Estado núm. 160. Referencia: BOE-A-1957-7998. Recuperado de https://www. boe.es/boe/dias/1957/06/20/pdfs/A00443-00454.pdf

Reino de España. Ministerio de Vivienda. (20 de junio de 2008). Por el que se aprueba el texto refundido. [Real Decreto Legislativo 2]. Boletín Oficial del Estado núm. 154. Referencia: BOE-A-2008-10792. Recuperado de https://www.boe.es/boe/ dias/2008/06/26/pdfs/A28482-28504.pdf

García, E. (2006). Los Principios de la nueva ley de expropiación forzosa. Cizur Menor (Navarra): Thomson Civitas.

García, F. M. (2007). El derecho de propiedad en la constitución española de 1978. Santiago de Cali: Criterio Jurídico/Pontificia Universidad Javeriana de Cali. Página 281-294. Recuperado de http://dialnet.unirioja.es/servlet/articulo?codigo $=2668487$

Pérez, J. A. (2016). Conceptualización de la función social de la propiedad en el derecho español y colombiano. Revista Jurídica Mario Alario D'Filippo, VIII (16), 176-191. 
Jimmy Antony Pérez Solano es profesor e investigador de la División de Derecho de la Universidad del Norte (BarranquillaColombia). Abogado de la Universidad Nacional de Colombia y especialista en derecho privado-económico de la misma universidad. Especialista en gestión pública e instituciones administrativas y magíster en derecho público para la gestión administrativa de la Universidad de Los Andes. Especialista en derecho administrativo y financiero. Diploma de Estudios avanzados (DEA) y doctor en derecho de la Universidad de Salamanca-España. https://orcid.org/0000_0003_0326_563X. 